https://doi.org/10.30910/turkjans.595231

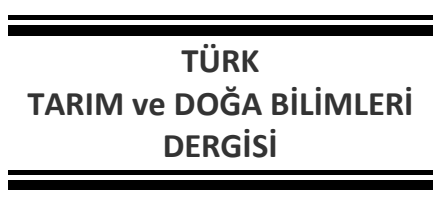

TÜRK

DERGISI

\section{Araştırma Makalesi \\ Malatya İlindeki Etlik Piliç İşletmelerinin Teknik ve Yapısal Özellikleri}

www.dergipark.gov.tr/turkjans
TURKISH

JOURNAL Of AGRICULTURAL and NATURAL SCIENCES

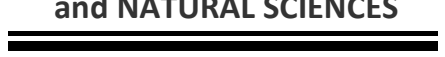

\author{
Turgay ŞENGÜL ${ }^{1 *}$, Ömer Faruk BOYRAZ ${ }^{2}$ \\ ${ }^{1}$ Bingöl Üniversitesi Ziraat Fakültesi Zootekni Bölümü-Bingöl \\ ${ }^{2}$ Bingöl Üniversitesi Fen Bilimleri Enstitüsü Zootekni ABD-Bingöl \\ *Sorumlu yazar: tsengul2001@yahoo.com
}

Geliş Tarihi: 26.03.2019

Düzeltme Geliş Tarihi: 26.04.2019

Kabul Tarihi: 27.06.2019

\title{
Özet
}

Bu çalışma, Malatya ilinde bulunan etlik piliç işletmelerinin teknik ve yapısal özelliklerinin belirlenmesi amacıyla yürütülmüştür. Araştırma materyalini, sözleşmeli yetiştiricilik yapan toplam 77 adet etlik piliç işletmesi oluşturmuştur. Elde edilen sonuçlara göre, işletmelerin tümünün işletme sahiplerine ait olduğu ve 1-2 kümesten oluştuğu saptanmıştır. İşletmelerde, mevcut kapasitenin 10.000-20.000 adet/devre ve kapasite kullanım oranının $\% 89$ olduğu belirlenmiştir. Üreticilerde yaş ortalaması 46.8 olup, $\% 46$ 'sı ilkokul mezunudur. Deneyim süresi 6 yıldan fazla olan üreticilerin oranı \%63.2 olarak bulunmuştur. Kümeslerde ısı kaynağı olarak, \%94.9 oranında soba kullanılmakta, havalandırma intiyacı ise \%93.2 oranında fanlarla sağlanmaktadır. Kümeslerin tamamında askılı yuvarlak yemlikler ve damlalıklı nipel suluklar kullanılmaktadır. Kümeslerde $\mathrm{m}^{2 \prime}$ ye konulan hayvan sayısı 13 adet (\%69.9) veya daha fazladır. Besi sonunda hayvan başına tüketilen ortalama yem miktarı $4.1 \mathrm{~kg}$, canlı ağırık ise 2.5 kg'dır. İşletmelerin tamamında dış kaynakıı hibrit kullanılmakta olup, besi dönemindeki ölüm oranı \%5-6 civarındadır. Sonuç olarak, Malatya ilindeki etlik piliç üretiminin sorunlarının genelde ülke genelindeki sorunlarla genelde benzer olduğu ve temel sorunlarının daha çok eğitim, kredi, yem ve hastalıklar olduğu saptanmıştır.

Anahtar kelimeler: Malatya, etlik piliç, broiler işletmesi, üretici.

\section{Technical and Structural Characteristics of the Broiler Poultry Farms in the Province of Malatya}

\begin{abstract}
This study was carried out with the purpose of determining the technical and structural characteristics of the broiler poultry farms in the province of Malatya in Turkey. The study material consisted of a total of 77 broiler poultry farms that were taking part in contract farming. According to the results, it was found that all the farms belonged to the owners and consisted of 1-2 poultry houses. The existing capacities of the farms were 10.000-20.000 individuals/rotation, and the rate of capacity utilization was $89 \%$. The mean age of the producers was 46.8 , and $46 \%$ were primary school graduates. The ratio of the producers with more than 6 years of experience was found as $63.2 \%$. The sources of heating for the poultry-houses were stoves by $94.9 \%$, and $93.2 \%$ of the establishments achieved ventilation by fans. All poultry houses used hanged round feeders and dripping nipple drinkers. The number of animals in the poultry houses per $\mathrm{m}^{2}$ was 13 individuals (69.9\%) or more. At the end of the fattening period, the feed amount consumed by each animal was $4.1 \mathrm{~kg}$, while the mean live weight was $2.5 \mathrm{~kg}$. All farms used foreign hybrids, and the mortality in the fattening period was about 5-6\%. Consequently, it was determined that the problems in producing broiler poultry in the province of Malatya were usually similar to the problems in the entire country, and the main problems were usually education, credits, feeds and diseases.
\end{abstract}

Key words: Malatya, broiler, poultry farms, producer. 


\section{Giriş}

Et tavukçuluğu, üretim süresinin çok kısa olması, birim alanda yoğun üretim yapılabilmesi, yemin ete dönüşüm oranının yüksek olması, iş gücünün diğer tarımsal işletmelere göre daha düşük olması ve kırmızı etle karşılaştırıldığında çok daha ucuza mal olması gibi nedenlerle diğer tarımsal faaliyetlere göre daha avantajlı olduğundan hızla gelişmiş ve endüstriyel bir yapı kazanmıştır. Bu sektör; üretici, yetiştirici, işleyici ve sanayicisi ile entegrasyonu, sözleşmeli üretim modeli ile pazarlamada modern yöntemleri uygulayan, yem, araç ve gereç, aşı ve ilaç, gıda sanayinin diğer alanlarıyla bağlantılı ve sonuçta da ülke nüfusunun protein ihtiyacının önemli bir kısmını karşılamasıyla hayvansal üretimde farklı bir yere sahiptir. Türkiye'de bu alanda $1990^{\prime}$ I yıllarda yapılan modern yatırımlarla üretim tesisleri sayısal ve kapasite yönüyle artmış ve 2000 'li yıllarda $A B$ standartlarında üretim yaygınlaşmıştır (Güneş, 2018). 2015 yılı istatistiklerine göre ülkemizdeki 9.676 ticari etlik piliç işletmesindeki 14.415 adet kümeste üretim yapılmaktadır. Ülkemiz, son yıllarda büyük bir gelişme göstererek dünyanın önde gelen tavuk eti üreticisi ülkeleri arasına girmiştir. Tavuk eti üretimimiz 2018 yılında 2.156.671 tona ulaşmıştır (TÜiK, 2018).

Türkiye'nin hayvancılık sektörü içinde, kanatlı eti sektörü en gelişmiş olan ve rekabet etme potansiyeli en yüksek olan sektör olmasına rağmen sektörün önemli sorunları da mevcuttur. Bu sorunlar, üretimde maliyetlerin yüksekliği, girdilerde dışa bağımlılık, tüketimin gelişmiş ülkelere göre düşük düzeylerde olması, istikrarsız döviz kuru ve ihracat ile ilgili sorunlar olarak sıralanabilir. Özellikle maliyetlerin yüksekliği sektörün gelişmesini engelleyen başlıca sorun olarak göze çarpmaktadır. Maliyetin ise \%70'ini yem giderleri oluşturmaktadır Kanatı yemlerinin temel hammaddeleri olan mısır ve soyanın büyük oranda ithalatla sağlanması, sektörün dışa bağımııı̆ııın arttırmaktadır. Bunun dışında, ülkemizin damızlık üretimi açısından da dışa bağımlı olması, dövizde öngörülemeyen değişmeler ve ihracatla ilgili bazı sorunlar da sektörün önemli sorunları olarak sayılabilir (Keskin ve Demirbaş, 2012).

Bu çalışma, Malatya ili ve ilçelerinde sözleşmeli üretim yapmakta olan etlik piliç işletmelerinin teknik ve yapısal özelliklerini belirlemek ve sorunlarını ortaya koymak amacıyla yapılmıştır.

\section{Materyal ve Yöntem}

Bu çalışmanın ana materyalini, Malatya ili ve ilçelerinde (Akçadağ, Arguvan, Yazıhan ve Yeşilyurt) faaliyet gösteren 77 adet etlik piliç işletmesinden anket yoluyla elde edilen veriler oluşturmuştur. Anket çalışmaları, hazırlanan anket formları ile söz konusu işletmeler gezilerek ve sahipleri ile yüz yüze görüşmek suretiyle yapılımışır. Çalışmada, anket sayısı ana kitle oranlarına dayalı, kümelendirilmemiş tek aşamalı basit tesadüfi olasılık örneklemesi ile belirlenmiştir (Güneş ve Arıkan, 1988). Araştırmada, anket uygulanacak işletme sayısının belirlenmesinde \%5 hata payı ve \%95 güvenirlilik sınırları içerisinde çalışılmıştır.

Anket yapılan işletmelerin ilçelere göre dağılımı; Malatya merkez 3 adet, Akçadağ 29 adet, Arguvan 1 adet, Yazıhan 16 adet, Yeşilyurt 28 adet şeklindedir. Hazırlanan anket formlarında, işletmelerin teknik ve yapısal özelliklerini ortaya koyacak sorulara yer verilmiştir. Elde edilen verilerin istatistiksel açıdan değerlendirilmesinde SPSS 19.0 programı kullanılmıştır.

\section{Bulgular ve Tartışma}

Çalışmada, Malatya merkez ve 5 ilçesinde üretim yapan 77 adet etlik piliç işletmesi incelenmiştir. Işletmelerin tamamının mülk durumunda ve 1-2 kümesten meydana geldiği saptanmıştır. Araştırmanın yürütüldüğü işletmelerin ilçeler bazındaki dağılımları Çizelge 1'de verilmiştir.

Çizelge 1. İşletmelerin ilçeler bazındaki dağııımı

\begin{tabular}{lcc}
\hline İlçeler & Sayı (adet) & Oran (\%) \\
\hline Akçadağ & 29 & 37.7 \\
Yeşilyurt & 28 & 36.4 \\
Yazıhan & 16 & 20.7 \\
Arguvan & 1 & 1.3 \\
Merkez & 3 & 3.9 \\
\hline Toplam & 77 & 100.0 \\
\hline
\end{tabular}

Çizelge 1 'de etlik piliç işletmelerinin daha çok 2 ilçede (Akçadağ \%37.7 ve Yeşilyurt \%36.4) yoğunlaşmış olduğu görülmektedir. İşletmelere ait kümeslerin kapasiteleri incelendiğinde, 10.00020.000 adet/devre kapasiteli olanların oranı \%46.7 ile ilk sırada, 20.001-30.000 adet/devre kapasiteli olanların oranı ise $\% 29.9$ ile 2 . sırada olduğu görülmektedir. İşletmelere ait kümeslerin kapasiteleri Çizelge 2'de verilmiştir. 
Çizelge 2. İşletmelerdeki kümeslerin kapasite bakımından dağıımı

\begin{tabular}{cccccc}
\hline \multicolumn{7}{c}{ Kapasite (adet/devre) } \\
\hline İlçeler & $\mathbf{5 . 0 0 0 - 1 0 . 0 0 0}$ & $\mathbf{1 0 . 0 0 1 - 2 0 . 0 0 0}$ & $\mathbf{2 0 . 0 0 1 - 3 0 . 0 0 0}$ & $\mathbf{3 0 . 0 0 0}$ & Toplam \\
\hline Akçadağ & 3 & 13 & 12 & 1 & 29 \\
Yeşilyurt & 6 & 13 & 6 & 3 & 28 \\
Yazıhan & 4 & 7 & 4 & 1 & 16 \\
Arguvan & - & 1 & - & - & 1 \\
Merkez & - & 2 & 23 & 5 & 3 \\
\hline Toplam & 13 & 36 & & 5 & 77 \\
\hline
\end{tabular}

Türkyılmaz (2006) Aydın ilinde yapmış olduğu çalışmada, incelediği 62 adet etlik piliç işletmesinin $\% 12.9^{\prime}$ unun 0-10.000 ölçekli, \%51.6'sının 10.00120.000 ölçekli ve $\% 35.5^{\prime}$ inin ise 20.0001 ve üzeri olduğunu bildirmiştir. Benzer şekilde, Yüzbaşı (2012)'da Bandırma ilçesindeki etlik piliç işletmelerinin \%68'inin 10.000-20.000 adet/devre kapasiteli, \%22'sinin 20.000-30.000 adet/devre kapasiteli olduğunu açıklamıştır. Diğer bir çalışmada ise, Bolu ilinde üretim yapan etlik piliç kümeslerinin \%33.3'ünün 1.000-5.000, \%38.9'unun 5.001-10.000, \%24'ünün 10.001-25.000 ve \%3.7'sinin ise 25.00050.000 adet/devre kapasiteli olduğu saptanmıştır (Yeni, 2012).

Incelenen işletmelerin kuruluş yıllarına bakıldığında, işletmelerin 2002-2013 yılları arasında kurulduğu görülmektedir. İşletmelerin \%16.9'u 2008 ve 2010 yıllarında, \%14.3'ü 2007 yılında, \%10.4'ü 2004 ve 2006 yıllarında, \%6.5'i 2009 ve 2011 yıllarında, \%2.6'sı 2003 ve 2013 yıllarında, \%1.3'ü ise 2002 ve 2012 yıllarında kurulmuştur.

İlçeler itibariyle işletmelerin büyük bir kısmı (73 işletme) \%94.8'i şahsa ait olmakla birlikte özel bir firmayla sözleşmeli olarak üretim yaparken, \%3.8'i (3 işletme) kendi firmasına ait ve \%1.4'ü ise (1 işletme) şahsa ait olarak üretim yapmaktadır.

Etlik piliç üretiminde işletmelerin merkeze olan uzaklıkları nakliye masraflarının azaltılması ve pazarlama yönünden önemlidir. Incelenen işletmelerin Malatya merkeze olan uzaklıklarına bakıldığında, işletmelerin \%29.8'inin 21 km'den az, \%48'inin 21-39 km arasında ve \%22'sinin 39 km'den daha fazla olduğu görülmektedir. Bandırma ilçesinde yapılan çalışmada, işletmelerin merkeze olan uzaklığı bakımından \%15'inin 5-10 km arasında, \%52'sinin 10$20 \mathrm{~km}$ arasında ve \%33'ünün 20-30 km arasında olduğu bildirilmiştir (Yüzbaşı, 2012).

İşletmelerin arazi varlığı açısından dağılımları Çizelge 3'te verilmiştir. Çizelge 3 incelendiğinde, işletmelerin \%15.5'inin 5 dekar ve daha az, \%44.4'ünün 6-10 dekar arasında, \%24.6'sının 10-15 dekar arasında ve \%15.5'inin 15 dekar ve daha fazla araziye sahip oldukları anlaşılmaktadır.

Çizelge 3. İşletmelerin sahip oldukları arazi varlığının dağılımı

\begin{tabular}{cccccc}
\hline \multirow{2}{*}{ ilçeler } & \multicolumn{7}{c}{ Arazi varlığı (dekar) } \\
\cline { 2 - 6 } & $\mathbf{5}$ & $\mathbf{6 - 1 0}$ & $\mathbf{1 0 - 1 5}$ & $\mathbf{2 1 5}$ & Toplam \\
\hline Akçadağ & 3 & 15 & 6 & 5 & 29 \\
Yeşilyurt & 8 & 11 & 4 & 5 & 28 \\
Yazıhan & - & 7 & 7 & 2 & 16 \\
Arguvan & - & - & 1 & - & 1 \\
Merkez & 1 & 1 & 1 & - & 3 \\
\hline Toplam & 12 & 34 & 19 & 12 & 77 \\
\hline
\end{tabular}

Incelenen işletmelerin istihdam ettiği işçi sayısı bakımından değerlendirildiğinde, \%58.5'inin hiçbir ücretli işçi çalıştırmadığı ve işgücünün sahipleri tarafından sağlandığı, \%37.6'sının 1-2 işçi çalıştırdığı , \%3.9'unun ise 3-4 işçi istihdam ettiği saptanmıştır.

İşletmelerin kredi kullanma durumu bakımından dağılımları şöyledir; işletmelerin \%53.2'si finansman ihtiyaçlarını banka kredisiyle, \%35'i öz sermayesiyle ve \%21.8'i ise TKDK tarafından karşıladığı belirlenmiştir. Sonuçlar, Türkyılmaz (2006)'ın bulguları ile benzerlik göstermiştir.

İşletmelerin kapasite kullanımı bakımından durumları Çizelge 4'te verilmiştir. Kapasite kullanım oranı, kullanılan kapasitenin kurulu kapasiteye oranlanmasıyla bulunmuştur. İşletmeler genelinde kapasite kullanım oranı \%89 olarak belirlenmiştir.

Köse ve Durmuş (2014) Ordu ilinde yaptıkları çalışmada, kapasite kullanım oranını \%80.4 olarak bildirmişlerdir. Diğer bir çalışmada, Türkiye genelinde üretim yapan etlik piliç işletmelerinin kapasite kullanım oranının \%70 olduğu açıklanmıştır (Öztürk ve Durmuş, 2001). Bu çalışmada elde edilen sonuç, her iki bulguya göre daha yüksek olmuştur. 
Çizelge 4. İşletmelere ait kurulu kapasite ve kapasite kullanım oranları

\begin{tabular}{|c|c|c|c|c|c|}
\hline \multirow{2}{*}{$\begin{array}{l}\text { Kapasite } \\
\text { grupları }\end{array}$} & \multicolumn{2}{|c|}{ İşletme sayısı } & \multirow{2}{*}{$\begin{array}{c}\text { Kurulu kapasite } \\
\text { (adet/devir) }\end{array}$} & \multirow{2}{*}{$\begin{array}{c}\text { Kullanılan } \\
\text { kapasite } \\
\text { (adet/devir) }\end{array}$} & \multirow{2}{*}{$\begin{array}{c}\text { Kapasite kullanım } \\
\text { oranı (\%) }\end{array}$} \\
\hline & $\begin{array}{c}\text { Sayı } \\
\text { (adet) }\end{array}$ & $\begin{array}{c}\text { Oran } \\
(\%)\end{array}$ & & & \\
\hline $5.000-10.000$ & 13 & 16.8 & 9538.4 & 9000.0 & 94.3 \\
\hline $10.001-20.000$ & 36 & 46.7 & 15944.4 & 15162.5 & 95.0 \\
\hline $20.001-30.000$ & 23 & 29.8 & 26217.3 & 22683.0 & 86.5 \\
\hline$>30.000$ & 5 & 6.7 & 46200.0 & 39380.0 & 85.2 \\
\hline Toplam & 77 & 100.0 & 97900.1 & 87225.5 & 89.0 \\
\hline
\end{tabular}

İşletme sahiplerinin yaş durumlarına bakıldığında, genel yaş ortalaması 46.8 olarak saptanmıştır. ilçeler itibariyle, işletmecilerin \%19.7'sinin 41 yaşından küçük, \%52.6'sının 41-50 yaş arasında, \%27.7'sinin ise 50 yaşından daha büyük olduğu belirlenmiştir. Bu konuda yapılan çalışmalarda, işletme sahiplerinin ortalama yaşlarının, Sakarya'da 44.8, Düzce'de 48.4, Kocaeli'de 50.4 ve Bolu'da 46.4 olarak bildirilmiştir (Yeni, 2012). Bu çalışmanın sonuçları, bildirilen bulgularla benzerlik göstermiştir.

İsletme sahiplerinin eğitim durumları incelenmiş olup, işletmecilerin \%46'sını ilkokul, \%22.3'ü nün ortaokul, \%30.2'sinin lise ve \%1.5'inin üniversite mezunu olduğu görülmüştür. Donar (1994) Adana ve Mersin yöresinde etlik piliç üretimi yapan işletme sahiplerinin \%71.9'unun eğitim düzeyini ilkokul mezunu olarak bildirmiştir. Yenilmez (2005) ise, Çukurova yöresinde işletme sahiplerinin \%55.3'ünün ilkokul mezunu olduğunu açıklamıştır.
Kümes binalarının yapısal özelliklerine bakıldığında, kümes genişliği bakımından 12 m'den daha kısa olanların oranı \%29.5, 12-15 m arasında olanları oranı $\% 57.8$ ve $15 \mathrm{~m}$ 'den daha uzun olanların oranı ise \%12.7 olarak tesbit edilmiştir. Yüzbaşı (2012) Bandırma ilçesindeki kümeslerin genişliğinin $\% 97$ 'sinin 10 m'den daha dar, \%3'ünün 12 m'den daha geniş olduğunu saptamıştır. Kümes uzunluğu bakımından ise, \%62.4'ü 100-150 m arasında, \%37.6'sı 100 m'den daha kısadır. Yenilmez (2005) Çukurova yöresindeki kümeslerin \%97.5'inin 100 m'den daha kısa olduğunu bildirmiştir. İncelenen kümeslerin duvar yüksekliklerinin 2-2.5 $\mathrm{m}$ arasında değiştiği ve $\% 80.6$ 'sının $2.25 \mathrm{~m}$ veya daha yüksek olduğu belirlenmiştir. Yüzbaşı (2012) yaptığı çalışmada, kümes duvar yüksekliğinin 2.5 m'den daha fazla olanlarının oranını \%71 olarak bildirmiştir. İncelenen işletmelerde barınak planlarının kimler tarafından hazırlandığına ilişkin bilgiler Çizelge 5'te verilmiştir.

Çizelge 5. Kümes planlarının hazırlanma durumu

\begin{tabular}{cccccccc}
\hline & \multicolumn{2}{c}{ İşletme sayısı } & \multicolumn{3}{c}{ Kümes planlarının kim tarafından hazırlandığı (\%) } \\
\hline Kapasite grupları & Sayı (adet) & Oran (\%) & Kendisi & Mühendis & Özel & TKDK & Toplam \\
\hline $5.000-10.000$ & 13 & 16.8 & 92.3 & 7.7 & - & - & 100.0 \\
$10.001-20.000$ & 36 & 46.7 & 52.7 & 44.4 & 2.9 & - & 100.0 \\
$20.001-30.000$ & 23 & 29.8 & 26.0 & 56.5 & 13.0 & 4.5 & 100.0 \\
$>30.000$ & 5 & 6.7 & 20.0 & 60.0 & 20.0 & - & 100.0 \\
\hline Toplam & 77 & 100.0 & 47.7 & 42.3 & 8.9 & 1.1 & 100.0 \\
\hline
\end{tabular}

Işletmeler genelinde kümes planları \%47.7 oranında işletmecinin kendisi, \%42.3'ü mühendis, \%8.9'u özel firma ve \%1.1'i TKDK tarafından hazırlanmıştır. Yenilmez (2005) yaptığı çalışmada, Çukurova yöresindeki kümeslerin planlarının \%43.4'ünün kamu kuruluşlarından alındığı, \%45.3'ünün işletme sahipleri tarafından hazırlandığı, \%9.4'ünün mühendise hazırlatıldığı ve \%1.9'unun ise çevredeki yetiştiricilerden temin ettiği bildirilmiştir.

Incelenen kümeslerde çatı malzemesi olarak, $\% 82$ oranında sandviç panel, \%16.8'inde sac ve \%1.2'sinde kiremit kullanılmıştır. Büyük kapasiteli kümeslerde daha çok sandviç panel tercih edilmiştir. Bandırma ve Çukurova yöresinde çatı malzemesi için yaygın olarak eternit kullanıldığı bildirilmiştir (Yenilmez, 2005; Yüzbaşı, 2012). Kümes duvarlarında kullanılan malzemelere bakıldığında, \%92.4 oranında tuğla, \%7.6 oranında ise bims (pomza taşı) olduğu görülmüştür.

Kümeslerde kullanılan yemlik ekipmanlarının tamamının askılı yuvarlak yemlikler olduğu, sulukların ise damlalıklı nipel suluklar olduğu saptanmıştır. Çizelge 6'da kümeslerde yemlik başına düşen hayvan sayısı verilmiştir. 
Çizelge 6. Kümeslerde yemlik başına düşen hayvan sayısı

\begin{tabular}{ccccccc}
\hline & \multicolumn{2}{c}{ İşletme sayısı } & \multicolumn{3}{c}{ Yemlik başına düşen hayvan sayısı (\%) } \\
\hline Kapasite grupları & Sayı (adet) & Oran (\%) & $<\mathbf{4 0}$ adet & $\mathbf{4 0 - 5 0}$ adet & >50 adet & Toplam \\
\hline $5.000-10.000$ & 13 & 16.8 & 23.0 & 15.3 & 61.7 & 100.0 \\
$10.001-20.000$ & 36 & 46.7 & 22.4 & 38.8 & 38.8 & 100.0 \\
$20.001-30.000$ & 23 & 29.8 & 4.3 & 60.8 & 34.9 & 100.0 \\
$>30.000$ & 5 & 6.7 & - & 20.0 & 80.0 & 100.0 \\
\hline Toplam & 77 & 100.0 & 12.4 & 33.7 & 53.9 & 100.0 \\
\hline
\end{tabular}

Kümeslerin \%53.9'unda yemlik başına düşen hayvan sayısı 50 adetten fazla, \%33.7'sinde 40-50 adet arasında ve \%12.4'ünde 40 adetten az olarak belirlenmiştir. Kümeslerde kullanılan suluk sayılarına bakıldığında, \%62.3 oranında 1500-3000 adet arasında, \%25.9 oranında 1500 adetten az ve \%11.8 oranında 3000 adetten fazla suluk kullanıldığı gözlenmiştir. Suluk başına düşen hayvan sayısı bakımından, kümeslerin \%57.2'sinde suluk başına 10 adet veya daha fazla hayvan düşerken, \%42.8'inde 10 adetten az hayvan düşmektedir. Kümeslerde altlık materyali olarak, \%93.1 oranında odun talaşı, \%6.9 oranında ise saman kullanılmaktadır. Kapasite arttıkça, altıı olarak saman kullanımı da artmaktadır. Kümeslerin Isıtılmasında kullanılan ISI kaynakları bakımından soba ön plana çıkmaktadır. İşletmelerin \%94.9'u soba kullanmakta, \%5.1'i ise kaloriferle ısıtma yapmaktadır. Incelenen kümeslerin havalandırılması
\%90.7 oranında fanlarla, \%9.3'ü pencere, tünel vb ile sağlanmaktadır. Aydınlatma, tüm kümeslerde floresan ampuller ile yapılmaktadır.

İşletmelerin tamamında hayvan materyali olarak Ross 308 kullanılmaktadır. Kümeslerde yılda 6 devir üretim yapılmaktadır. İncelenen kümeslerin hiçbirinde verim kayıtları tutulmadığı belirlenmiştir. Besi süresi 40-45 gün arasında değişmektedir. Kümeslerin \%56.6'sında besi sonu canlı ağırlık 2.5 kg'dan fazla, karkas ağırlığı ise $\% 60.5$ oranında $\leq 1.8 \mathrm{~kg}$ olarak saptanmıştır. Incelenen işletmelerin tamamında kesimden 8 saat önce yemleme kesilmektedir. Yenilmez (2005) yaptığı çalışmada, kesimden 4-12 saat önce yemlemenin kesildiğini bildirmiştir. Arıç (1996) ise kesimden 4-8 saat önce yemlemenin kesildiğini açıklamıştır. Incelenen işletmelere ait bazı üretim bilgileri Çizelge 7'de verilmiştir.

Çizelge 7. İşletmelerin kapasite bazında bazı üretim bilgileri

\begin{tabular}{|c|c|c|c|c|c|}
\hline $\begin{array}{l}\text { Değişkenler/ } \\
\text { Kapasiteler }\end{array}$ & $5.000-10.000$ & $10.001-20.000$ & $20.001-30.000$ & $>30.000$ & Ortalama \\
\hline \multicolumn{6}{|c|}{ Civcivin temin edildiği yer } \\
\hline Firma & 100.0 & 100.0 & 95.5 & 100.0 & 98.9 \\
\hline Kendisi & 0.0 & 0.0 & 4.5 & 0.0 & 1.1 \\
\hline Toplam & 100.0 & 100.0 & 100.0 & 100.0 & 100.0 \\
\hline \multicolumn{6}{|c|}{ Besi süresi (gün) } \\
\hline $40-42$ & 0.0 & 0.0 & 8.6 & 0.0 & 2.5 \\
\hline $40-45$ & 76.9 & 30.5 & 13.0 & 40.0 & 33.7 \\
\hline $42-45$ & 23.1 & 47.4 & 13.0 & 0.0 & 29.8 \\
\hline 42 & 0.0 & 16.6 & 56.8 & 40.0 & 27.2 \\
\hline 45 & 0.0 & 5.5 & 8.6 & 20.0 & 6.8 \\
\hline Toplam & 100.0 & 100.0 & 100.0 & 100.0 & 100.0 \\
\hline \multicolumn{6}{|c|}{ Besi dönemi sonu canlı ağırlığı (kg) } \\
\hline$\leq 2.5$ & 30.7 & 44.4 & 50.0 & 40.0 & 43.4 \\
\hline$>2.5$ & 69.3 & 55.6 & 50.0 & 60.0 & 56.6 \\
\hline Toplam & 100.0 & 100.0 & 100.0 & 100.0 & 100.0 \\
\hline \multicolumn{6}{|c|}{ Besi dönemi sonu kesim ağırlığı (kg) } \\
\hline$\leq 1.8$ & 69.3 & 75.0 & 31.8 & 60.0 & 60.5 \\
\hline$>1.8$ & 30.7 & 25.0 & 68.2 & 40.0 & 39.5 \\
\hline Toplam & 100.0 & 100.0 & 100.0 & 100.0 & 100.0 \\
\hline
\end{tabular}


İşletmelerde yerleşim sıklığı (1 $\mathrm{m}^{2}$ alana konulan hayvan sayısı) uygulaması 9-18 adet arasında değişmekle birlikte, ortalama 13.3 adet olarak belirlenmiştir. Kümeslerin genel toplamı içerisinde, $\mathrm{m}^{2 \prime}$ ye konulan hayvan sayısı \%69.9 oranında 13 adet veya daha fazla, \%30.1 oranında ise 13 adetten az olarak tesbit edilmiştir. Kapasite arttıkça yerleşim yoğunluğu da artış göstermiştir. Yenilmez (2005) yaptığı çalışmada, kümeslerde yerleşim sıklığının 1217 arasında olduğunu bildirmiştir.

İncelenen işletmelerin tamamı karma yemleri firmalardan satın almaktadırlar. Kümeslerde besi süresi boyunca hayvan başına tüketilen yem miktarının ortalama $4.1 \mathrm{~kg}$ olduğu saptanmıştır. Bu değer, başka bir çalışmada 3.6-4.0 kg olarak bildirilmiştir (Yenilmez, 2005). Kümeslerde besi süresi boyunca ölüm oranları, kümeslerin \%42.8'inde \%5-6 arasında, \%37.1'inde \%4-5 arasında, \%42.8'inde \%5-6 arasında ve \%20.1'inde \%7 ve daha fazla olarak hesaplanmıştır. Bu değer, Erdem (1996) tarafından \%4.3, Yenilmez (2005) tarafından \%2-10 arasında bildirilmiştir.

İşletmelerin sorunları incelendiğinde genelde eğitim sorununun ilk sırada geldiği görülmektedir. İşletmelerin \%87.0'si eğitim, \%84.4'ü kredi, \%1.3'ü yem ve hastalık sorununu ilk sorun olarak görmektedirler. Etlik piliç işletmelerinin sorunlarını, Arıç (1996) yem, civciv, hastalık, işçilik ve ürün fiyatları olarak, Can (1996) altyapı, sağıı, yem ve pazarlama, Küçükaydın (1996) yem, civciv, hastalık, kredi, eğitim, organizasyon ve pazarlama olarak bildirmişlerdir. Yapılan diğer bir çalışmada ise, işletmelerin en önemli sorununun üretim maliyetlerinin yüksek olmasından dolayı kar marjının çok düşük olması olarak bildirilmiştir (Öztürk ve Durmuş, 2001).

\section{Sonuç ve Öneriler}

Malatya merkez ve ilçelerinde yürütülmüş olan bu çalışmada, işletmelerin sorunlarının diğer bölgelerdeki işletmelerden daha az olduğu ve bazı farklılıklar gösterdiği, sorunların özellikle eğitim ve kredi konusunda odaklandığı görülmüştür. Sonuçlar, etlik piliç işletmelerinin sorunlarının zamanla değiştiğini ve üretimle ilgili sorunların azaldığını göstermektedir. Sorunların çözümü açısından, Malatya'daki işletme sahiplerinin teknik ve finansman konularında eğitilerek üretim maliyetlerinin düşürülmesi ve kar marjlarının yükseltilmesi önem taşımaktadır.

¥: Bu çalışma Ö. Faruk BOYRAZ’ın Yüksek Lisans tezinden üretilmiştir.

\section{Kaynaklar}

Arıç, H. 1996. Çukurova Bölgesi Broiler Yetiştiriciliğinin Yapısı ve Sorunları. Çukurova Ünv., Fen Bilimleri Enstitüsü, Zootekni Anabilim Dalı, Yüksek Lisans Tezi. Adana.

Can, H. 1996. Türkiye Broiler Üretiminin Sorunları. Ulusal Kümes Hayvanları Sempozyumu 96, 2729 Kasım 1996, Adana.

Donar, H. 1994. Adana-Mersin Illerinde Broiler Üretim Ekonomisi. Çukurova Ünv., Fen Bilimleri Enstitüsü, Tarım Ekonomisi Anabilim Dalı, Yüksek Lisans Tezi, Adana.

Erdem, M. 1996. Tarsus Köy-Tür A.Ş Bağlantılı Broiler İşletmelerinin Verimlilik Yönünden Karşılaştırılması. Çukurova Ünv., Fen Bilimleri Enstitüsü, Zootekni Anabilim Dalı, Yüksek Lisans Tezi, Adana.

Güneş, T., Arıkan, R. 1988. Tarım Ekonomisi İstatistiği. Ankara Ünv. Ziraat Fak., Yayınları No: 1049, Ders Kitapları, No: 305, Ankara.

Güneş, E. 2018. Türkiye'de kanatlı et sektörünün ekonomik potansiyeli ve gelişimi. Dünya Gıda. Nisan 2018, 21 s.

Keskin, B., Demirbaş, N. 2012. Türkiye'de kanatlı eti sektöründe ortaya çıkan gelişmeler: Sorunlar ve öneriler. U.Ü. Ziraat Fakültesi Dergisi, 26(1): 117-130.

Köse, B., Durmuş, í. 2014. Ordu ilindeki tavukçuluk işletmelerinin genel yapısı, sorunları ve çözüm önerileri. Akademik Ziraat Dergisi, 3(2): 89-94.

Küçükaydın, H. 1996. Hatay ilindeki Tavukçuluk İşletmelerinin Yapısal Özellikleri, Ekonomik Durumları, Sorunları ve Çözüm Yolları. MKU Üniversitesi Fen Bilimleri Enstitüsü, Zootekni Anabilim Dalı, Yüksek Lisans Tezi, Hatay.

Öztürk, F., Durmuş, ì. 2001. Türkiye'de tavukçuluk işletmelerinin genel durumu. Tavukçuluk Araştırma Dergisi, 3(2):7-16.

TÜik, 2018. Türkiye İstatistik Kurumu. http://www.tuik.org.tr.

Türkyılmaz, K.M. 2006. Aydın ili broyler işletmelerinin yapısal ve teknik durumu üzerine bir araştırma. YYÜ Veteriner Fakültesi Dergisi, 17(1-2): 65-69.

Yenilmez, F. 2005. Çukurova Yöresindeki (Adana ve içel illerindeki) Broiler ve Yumurta Tavuğu İşletmelerinin Yetiştiricilik, Teknik ve Yapısal Özellikleri Üzerine Bir Araştırma. Çukurova Ünv., Fen Bilimleri Enstitüsü, Zootekni Anabilim Dalı, Doktora Tezi, Adana.

Yüzbaşı, Ş. 2012. Bandırma İlçesi Kasaplık Piliç İşlemelerinin Yapısal ve Fonksiyonel Özellikleri. Ankara Ünv., Fen Bilimleri Enstitüsü, Tarımsal 
Yapılar ve Sulama Anabilim Dalı, Yüksek Lisans Tezi, Ankara.

Yeni, A. 2012. Türkiye Broiler Sektöründe Üretim Kümeslerinin Ekonomik Yapısı ve Etkinlik Analizi: Doğu Marmara Bölgesi Örneği. Atatürk Ünv., Fen Bilimleri Enstitüsü, Tarım Ekonomisi Anabilim Dalı, Doktora Tezi, Erzurum. 